\title{
Acute lower gastrointestinal bleeding originating from an arteriovenous fistula of superior rectal artery
}

\author{
Alper Bozkurt • Meral Sözen • İsmail Kurbaș • \\ İsmail Bilgiç • Benan Kasapoğlu • Ișılay Nadir
}

Accepted: 11 May 2014 / Published online: 23 May 2014

(C) Springer-Verlag Berlin Heidelberg 2014

Dear Editor:

The most common acute causes of lower gastrointestinal (GI) hemorrhage are diverticulosis and angiodysplasia [1]. Arteriovenous fistula (AVF) of the intestine is an uncommon cause of GI hemorrhage [2]. AVF originating from the distal branch of superior rectal artery has never been described before and up to date as a cause of lower GI bleeding. Herein, we report a case of embolization of an $\mathrm{AVF}$ originated from the superior rectal artery end branch as a cause of acute lower GI bleeding.

An 80-year-old man, with prior history of acute lower GI bleeding episode resolved with supportive treatment 6 months ago, was admitted to our hospital with bright red blood per rectum bleeding. Flexible colonoscopy revealed proximal fresh bleeding without any specific bleeding site. The patient was then referred for a computed tomography (CT) scan. The CT initially suspected an abnormal vessel on the left lateral side wall of the rectum. However, as the patient's condition remained stable the hemoglobin value decreased despite transfusion, the patient was transferred to the interventional radiology suite for a mesenteric angiography with possible embolization.

\footnotetext{
A. Bozkurt $(\bowtie) \cdot$ İ. Kırbaș

Radiology Department, Turgut Özal University Hospital, Ankara, Turkey

e-mail: bozkurtalper@yahoo.com

M. Sözen • B. Kasapoğlu $\cdot$ I. Nadir

Internal Medicine Department, Turgut Özal University Hospital,

Ankara, Turkey

İ. Bilgiç

General Surgery Department, Turgut Özal University Hospital,

Ankara, Turkey
}

Angiography showed left superior rectal artery-originated AVF with the suspicion of bleeding. The superior rectal artery branch of AVF was superselectively catheterized with a $2.7 \mathrm{Fr}$ Progreat microcatheter (Terumo, Tokyo, Japan) and embolized with microcoils. Complete hemostasis was achieved after embolization. Very rare cases of inferior mesenteric AVFs have been reported, and a few of them were responsible of acute GI bleeding in the literature [2]. Most of the cases of acute lower GI hemorrhage are controlled with supportive treatment. Persistent bleeding with hemodynamic instability requires further investigation and management $[1,3]$. The major risk of embolization is bowel ischemia. As advancements in microcatheter technology have allowed embolization of distal arteries smaller than $1 \mathrm{~mm}$ in diameter, thus, the reported rate of colonic ischemia has reduced to approximately $3-4 \%$ in recent studies [1]. Here, we have presented a very rare case of embolization of an intestinal AVF originated from the end branch of superior rectal artery. We suggest that superselective embolization may be a more safe treatment option in some types of acute lower GI bleeding.

\section{References}

1. Zakeri N, Cheah SO (2012) A case of massive lower gastrointestinal bleeding: superior rectal artery pseudoaneurysm. Ann Acad Med Singap 41(11):529-531

2. Turkvatan A, Ozdemir Akdur P, Akdogan M, Cumhur T, Olcer T, Parlak E (2009) Inferior mesenteric arteriovenous fistula with ischemic colitis: multidetector computed tomographic angiography for diagnosis. Turk $\mathrm{J}$ gastroenterol: Off $\mathrm{J}$ Turk Soc Gastroenterol 20(1):67-70

3. Teng HC, Liang HL, Lin YH, Huang JS, Chen CY, Lee SC, Pan HB (2013) The efficacy and long-term outcome of microcoil embolotherapy for acute lower gastrointestinal bleeding. Korean J Radiol: Off J Korean Radiol Soc 14(2):259-268 